\title{
Formation of silicon nanocrystals in sapphire by ion implantation and the origin of visible photoluminescence
}

\author{
S. Yerci, ${ }^{a}$ U. Serincan, and I. Dogan \\ Department of Physics, Middle East Technical University, 06531 Ankara, Turkey \\ S. Tokay \\ Department of Physics, Kirikkale University, 71450 Kirikkale, Turkey \\ M. Genisel \\ Department of Chemistry, Middle East Technical University, 06531 Ankara, Turkey
}

A. Aydinli

Department of Physics, Bilkent University, 06531 Ankara, Turkey

R. Turan

Department of Physics, Middle East Technical University, 06531 Ankara, Turkey

(Received 17 March 2006; accepted 6 July 2006; published online 4 October 2006)

\begin{abstract}
Silicon nanocrystals, average sizes ranging between 3 and $7 \mathrm{~nm}$, were formed in sapphire matrix by ion implantation and subsequent annealing. Evolution of the nanocrystals was detected by Raman spectroscopy and x-ray diffraction (XRD). Raman spectra display that clusters in the matrix start to form nanocrystalline structures at annealing temperatures as low as $800{ }^{\circ} \mathrm{C}$ in samples with high dose Si implantation. The onset temperature of crystallization increases with decreasing dose. Raman spectroscopy and XRD reveal gradual transformation of Si clusters into crystalline form. Visible photoluminescence band appears following implantation and its intensity increases with subsequent annealing process. While the center of the peak does not shift, the intensity of the peak decreases with increasing dose. The origin of the observed photoluminescence is discussed in terms of radiation induced defects in the sapphire matrix. (C) 2006 American Institute of Physics.
\end{abstract}

[DOI: $10.1063 / 1.2355543$ ]

\section{INTRODUCTION}

Observation of intense photoluminescence (PL) from nanocrystalline silicon ${ }^{1}$ and its charge storing capabilities has attracted much attention because of its potential applications in optoelectronic ${ }^{2,3}$ and charge storing devices. ${ }^{4}$ Silicon nanocrystal embedded in $\mathrm{SiO}_{2}\left(\mathrm{Si}-\mathrm{nc} / \mathrm{SiO}_{2}\right)$ structures have been widely studied for both applications. Nevertheless, the origin of the PL from Si-nc/ $\mathrm{SiO}_{2}$ structures is still controversial. It has been proposed to originate from the quantum confinement of carriers in Si nanocrystals, ${ }^{5,6}$ surface states such as $\mathrm{Si}=\mathrm{O}$ bonds formed on the surface of the nanocrystals, ${ }^{7}$ and defects in the oxide. ${ }^{8} \mathrm{SiO}_{2}$ films on $\mathrm{Si}$ substrate are widely used for charge storage for it has superior electrical properties and it can be easily grown thermally on $\mathrm{Si}$ substrates. On the other hand, shrinking dimensions of gate dielectrics led researchers to look for alternative materials having similar insulating properties as $\mathrm{SiO}_{2}$ but with higher dielectric constant than $\mathrm{SiO}_{2} \cdot \mathrm{Al}_{2} \mathrm{O}_{3}$ is a promising candidate for gate oxide material because its dielectric constant is twice as much as that of $\mathrm{SiO}_{2}$ and the band gap of $\mathrm{Al}_{2} \mathrm{O}_{3}(9.2 \mathrm{eV})$ is very similar to that of $\mathrm{SiO}_{2}(8.7 \mathrm{eV})$. Furthermore, semiconductor nanocrystals in $\mathrm{Al}_{2} \mathrm{O}_{3}$ matrix can be considered as a suitable structure for optical device

\footnotetext{
a) Author to whom correspondence should be addressed; electronic mail: syerci@metu.edu.tr
}

applications due to optical transparency of $\mathrm{Al}_{2} \mathrm{O}_{3}$. The production of nonvolatile memory devices containing nanocrystals in high- $k$ oxides, such as alumina, has been studied extensively. ${ }^{10}$ Thin films of $\mathrm{Al}_{2} \mathrm{O}_{3}$ can be grown on Si substrate by using present well-developed integrated circuit processes. The reverse is also true. Si-nc can be formed in $\mathrm{Al}_{2} \mathrm{O}_{3}$ matrix with various methods such as pulsed laser deposition, ${ }^{9}$ cosputtering, ${ }^{11}$ electron beam coevaporation, ${ }^{12}$ electrochemistry, ${ }^{13}$ and ion implantation. ${ }^{14-16}$ Among these methods, ion implantation is of particular interest because of its compatibility with the existing complementary metaloxide semiconductor (CMOS) technology and its superior control over the position and dose of the ions, therefore of nanocrystals.

In this study, silicon nanocrystals were formed in $\alpha-\mathrm{Al}_{2} \mathrm{O}_{3}$ matrix by ion implantation and followed by an annealing process in the temperature range of $600-1100{ }^{\circ} \mathrm{C}$. Evolution of nanocrystal formation and their optical emission properties have been investigated by XRD, Raman, and PL spectroscopies as a function of the implanted Si dose and annealing temperature. XRD was employed to calculate the size of the nanocrystals. Moreover, systematic correlation between the Raman signals of varying doses and annealing parameters was used to track the amorphous to crystalline phase changes and the deviation of stress on nanocrystals. Finally, detailed PL measurements were performed to search for the origin of the emission mechanism. 


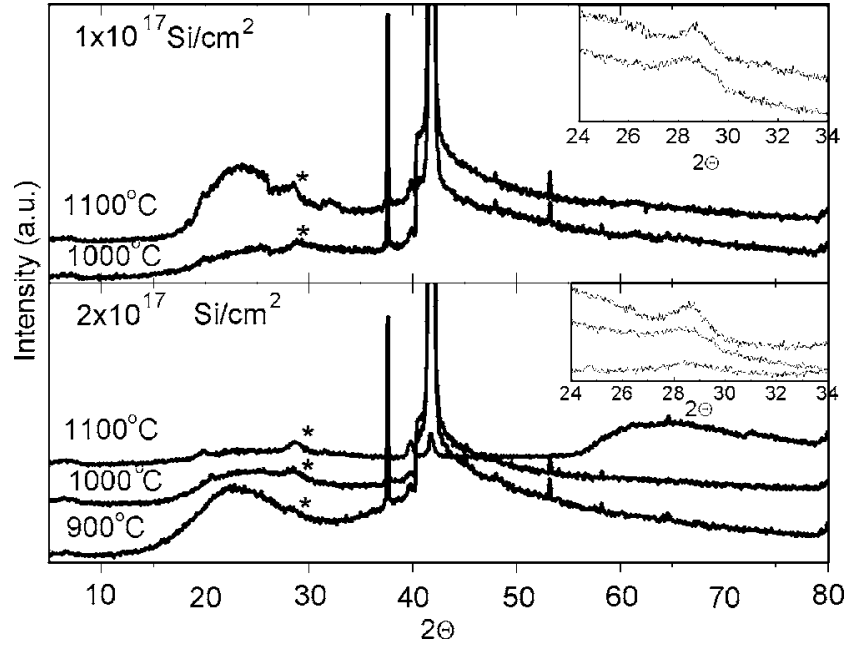

FIG. 1. The evolution of XRD signal of Si implanted $\alpha-\mathrm{Al}_{2} \mathrm{O}_{3}$ matrix as a function of implantation dose and annealing temperature. $\left({ }^{*}\right)$ indicates the $\mathrm{Si}$ (111) peaks. Inset shows details of Si (111) peaks.

\section{EXPERIMENT}

$C$-plane oriented $\alpha-\mathrm{Al}_{2} \mathrm{O}_{3}$ substrates were implanted with $100 \mathrm{keV}{ }^{28} \mathrm{Si}^{+}$ions at doses of $1 \times 10^{16}, 1 \times 10^{17}$, and $2 \times 10^{17} \mathrm{Si} / \mathrm{cm}^{2}$ and annealed at 600, 700, 800, 900, and $1100{ }^{\circ} \mathrm{C}$ in $\mathrm{N}_{2}$ ambient for $2 \mathrm{~h}$ to induce Si nanocrystal formation. The projected range $\left(R_{p}\right)$ of the $\mathrm{Si}$ ions was calculated as $81 \mathrm{~nm}$ using TRIM software. ${ }^{17}$ All PL measurements were conducted at room temperature with the $488 \mathrm{~nm}$ line of an $\mathrm{Ar}^{+}$laser, operated at $300 \mathrm{~mW}$. The emitted light was detected with a photomultiplier tube. Raman measurements were employed in backscattering geometry at room temperature using $632.8 \mathrm{~nm}$ as light source of a confocal microRaman (HR800, Jobin Yvon), attached with Olympus microanalysis system and a charge-coupled device (CDD) camera providing a resolution of $\sim 1 \mathrm{~cm}^{-1}$. XRD measurements were conducted with a standard X-ray powder diffractometer, using $\mathrm{Cu} K \alpha$ radiation. Conventional BraggBrentano $\Theta-2 \Theta$ scans were employed with scans between $5^{\circ}$ and $80^{\circ}$ at $0.02^{\circ}$ steps. Acquisition time per angular steps of $24 \mathrm{~s}$ was used to enhance the signal to noise ratio. The data used were the average of three scans. The full width at half maximum (FWHM) of the diffraction peak $\left(0.122^{\circ}\right)$ of a standard sample of microcrystalline powder $\mathrm{Si}$ was recorded to eliminate the instrumental line broadening. The Si (111) peak at $28.4^{\circ}$ was used for both the correction of the instrumental broadening and the calculation of the nanocrystal sizes.

\section{RESULTS AND DISCUSSION}

\section{A. X-ray diffraction (XRD)}

The XRD signals corresponding to $\mathrm{Si}(111)$, with $2 \Theta$ value around $28.6^{\circ}$, became evident at annealing temperatures of 900 and $1000{ }^{\circ} \mathrm{C}$ for the samples implanted with doses of $2 \times 10^{17}$ and $1 \times 10^{17} \mathrm{Si} / \mathrm{cm}^{2}$, respectively. Measured spectra from samples annealed at 900, 1000, and $1100{ }^{\circ} \mathrm{C}$ with the dose of $2 \times 10^{17} \mathrm{Si} / \mathrm{cm}^{2}$ as well as those annealed at 1000 and $1100{ }^{\circ} \mathrm{C}$ with the dose of 1 $\times 10^{17} \mathrm{Si} / \mathrm{cm}^{2}$ are displayed in Fig. 1. The formation of

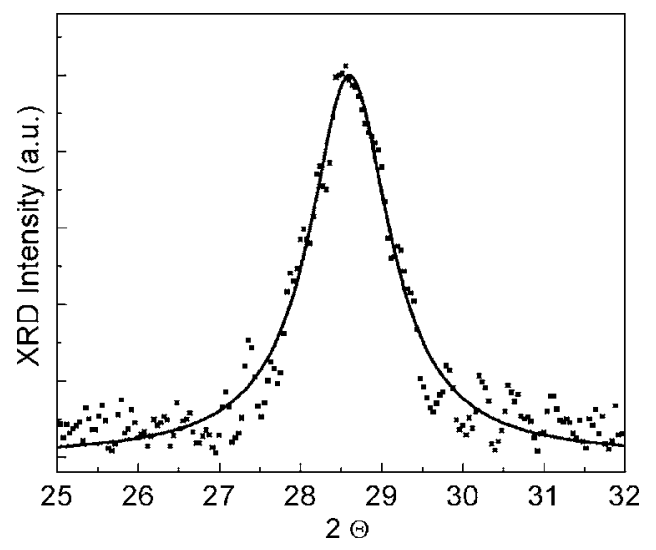

FIG. 2. Si (111) XRD peak at $28.6^{\circ}$. The solid line is a fit to data using a pseudo-Voigt function.

Si-nc having (111) direction has been extensively studied in other matrices such as $\mathrm{SiO}_{2}$ using XRD. ${ }^{18,19}$ Moreover, the same structure was studied in sapphire matrix with electron diffraction. ${ }^{14,15}$ As shown in the inset of Fig. 1, Si (111) XRD signal broadens with decreasing annealing temperatures enabling us to calculate the average grain sizes of nanocrystals and their evolution with the annealing temperature. Size calculation using XRD is simple and nondestructive which provides an average value for the nanocrystals size. The average nanocrystal size determination was performed using Scherrer's formula, which agrees well with other experimental techniques such as high-resolution transmission electron microscopy (HRTEM), when uncertainties for all are taken into account. ${ }^{19}$ Scherrer's formula is given as

$$
D=\frac{k \lambda}{\beta \cos \Theta},
$$

where $D$ is the average grain size, $\beta$ is the FWHM of the diffraction peak after the elimination of instrumental line broadening, $\theta$ is the Bragg angle, $\lambda$ is the wavelength of the $\mathrm{x}$ ray $(0.154 \mathrm{~nm})$, and $k=0.89$ is the Scherrer constant. The residual $\mathrm{Cu} K \alpha_{2}$ was corrected by using the Rachinger correction method which assumes the intensity of the $K \alpha_{2}$ as half as that of $K \alpha_{1} \cdot{ }^{20}$ The background correction was performed assuming quadratic polynomial background which gives the best fit. Figure 2 displays the data and the subsequent fit to the XRD signal from the sample implanted with $2 \times 10^{17} \mathrm{Si} \mathrm{cm}^{-2}$ and annealed at $1100{ }^{\circ} \mathrm{C}$. Peak profiles were assumed to be pseudo-Voigt, which is a combination of Gaussian and Cauchy line shapes.

Following Scherrer's formula, average nanocrystal sizes are estimated to be $7.2 \pm 0.2$ and $5.1 \pm 0.2$ in samples implanted with the dose of $2 \times 10^{17} \mathrm{Si} / \mathrm{cm}^{2}$ and subsequently annealed at 1100 and $1000{ }^{\circ} \mathrm{C}$, respectively. Similarly, in samples implanted with the dose of $1 \times 10^{17} \mathrm{Si} / \mathrm{cm}^{2}$, average Si nanocrystal sizes are found to be $7.0 \pm 0.2$ and $3.9 \pm 0.2 \mathrm{~nm}$ for annealing temperatures of 1100 and $1000{ }^{\circ} \mathrm{C}$, respectively. These values of nanocrystal sizes are in good agreement with the reported values as determined from HRTEM analysis. ${ }^{16}$ The uncertainties given in $D$ values are statistical errors associated with the determination of the FWHM of Si (111) Bragg peak only. While stress may induce additional 


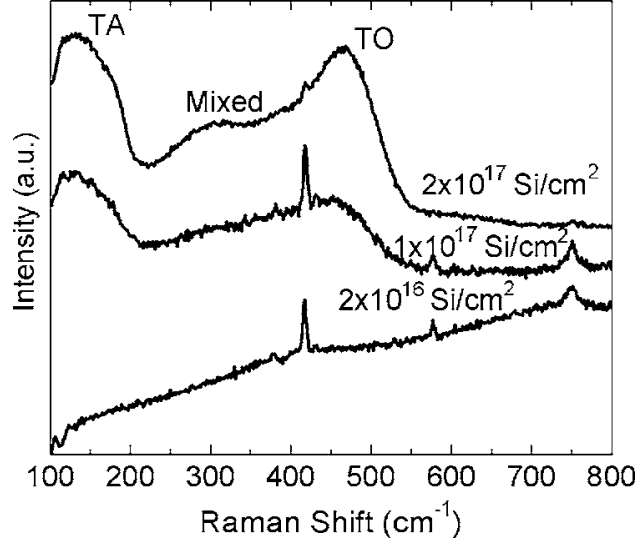

FIG. 3. Raman spectra of $\alpha-\mathrm{Al}_{2} \mathrm{O}_{3}$ implanted with doses of $2 \times 10^{16}, 1$ $\times 10^{17}$, and $2 \times 10^{17} \mathrm{Si} / \mathrm{cm}^{2}$.

broadening, it is difficult to deconvolute the effect of finite size and stress from the FWHM of the diffraction peak. Tensile or compressive stress will also cause a shift in the Bragg diffraction peak position from its bulk counterpart which can be used to evaluate the magnitude and direction of stress. We, therefore, used the position of the diffraction peak position to evaluate stress from the XRD data.

The measured lattice constant for the nanocrystals is always smaller than the lattice constant of $5.43 \AA$ obtained from the reference sample of polycrystalline $\mathrm{Si}$, for all doses of implantation and temperatures of annealing, which implies compressive stress on nanocrystals with the mean lattice compression of $\Delta a / a=0.04 \%-0.11 \%$. This result can be explained with the lattice mismatch between the nanocrystals and the host matrix. A reasonable explanation for this stress requires a careful examination of the phase transformations of both the nanocrystals and the host matrix during the ion implantation and annealing process. While the nanocrystals formed at lower annealing temperatures (800-900 ${ }^{\circ} \mathrm{C}$ ) are mostly amorphous they crystallize after annealing at around $1100{ }^{\circ} \mathrm{C} .{ }^{21}$ For the surrounding matrix, although no phase formation of $\mathrm{Al}_{2} \mathrm{O}_{3}$ other than $\alpha-\mathrm{Al}_{2} \mathrm{O}_{3}$ was observed in XRD measurements, the creation of $\Theta-\mathrm{Al}_{2} \mathrm{O}_{3}$ was previously reported after annealing of amorphized $\mathrm{Al}_{2} \mathrm{O}_{3}$ matrix by ion implantation with the dose of $5 \times 10^{16} \mathrm{Si} / \mathrm{cm}^{2} .{ }^{14} \Theta-\mathrm{Al}_{2} \mathrm{O}_{3}$ has a monoclinic structure with lattice constants of $a=11.79 \AA, b=2.91 \AA$, and $c=5.62 \AA$. The minimum lattice mismatch is about $3.4 \%$ which can be responsible from the compressive stress. On the other hand, $\alpha-\mathrm{Al}_{2} \mathrm{O}_{3}$ is the most stable phase among the $\mathrm{Al}_{2} \mathrm{O}_{3}$ phases which is formed after $1000-1100{ }^{\circ} \mathrm{C}$ annealing. $\alpha-\mathrm{Al}_{2} \mathrm{O}_{3}$ has a hexagonal structure with the lattice constants of 4.758 and $12.991 \AA$. Therefore, in the present case, minimum lattice mismatch can be calculated as $14 \%$ between the nanocrystals and the host matrix. This mismatch should generate large amounts of mechanical stress on Si nanocrystals.

\section{B. Raman spectroscopy}

Raman spectra of as-implanted samples are given in Fig. 3. The peaks at around 418,577 , and $750 \mathrm{~cm}^{-1}$ are from the crystalline host matrix. The intensity of these peaks decreases with increasing doses because of partial amophiza-

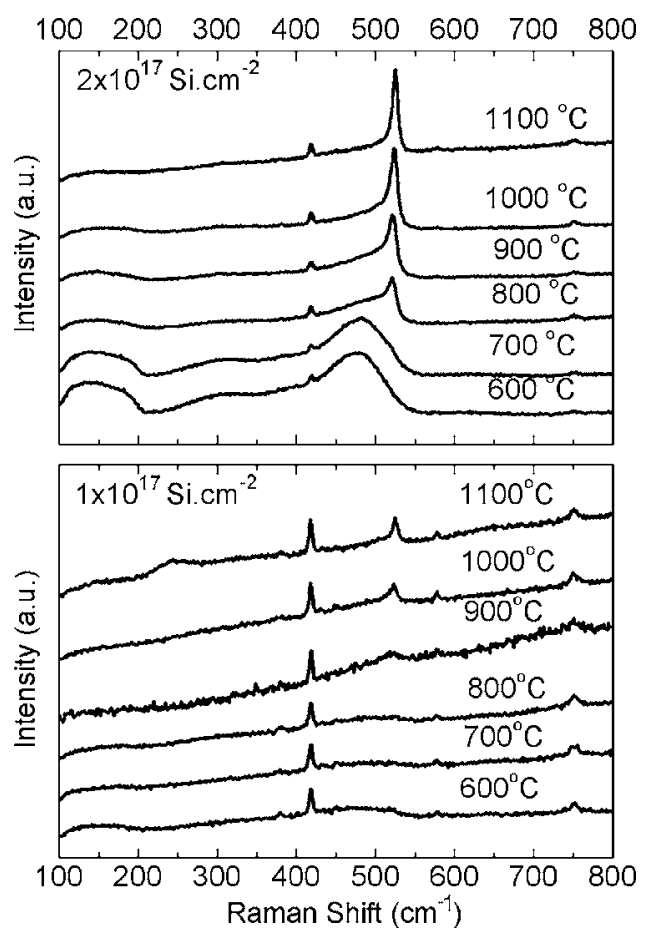

FIG. 4. The evolution of Raman signal for the doses of $1 \times 10^{17}$ and 2 $\times 10^{17} \mathrm{Si} / \mathrm{cm}^{2}$ implanted samples with annealing temperature.

tion of the matrix. While no Raman signals for $\mathrm{Si}-\mathrm{Si}$ bonds were observed from the sample with the dose of 2 $\times 10^{16} \mathrm{Si} / \mathrm{cm}^{2}$, Raman signals typical for amorphous $\mathrm{Si}$ were detected in the sample with doses of $1 \times 10^{17}$ and 2 $\times 10^{17} \mathrm{Si} / \mathrm{cm}^{2}{ }^{22}$ The bands recorded from higher dose implanted samples are described as transverse acoustic (TA) band around $150 \mathrm{~cm}^{-1}$, transverse optical (TO) band around $480 \mathrm{~cm}^{-1}$, and mixed acoustic-optical band around $310 \mathrm{~cm}^{-1}$. One could safely conclude that implantation with the dose of $2 \times 10^{16} \mathrm{Si} / \mathrm{cm}^{2}$ is not sufficient to generate amorphous Si clusters detectable with Raman spectroscopy (Fig. 3) and XRD. Annealing at $1100{ }^{\circ} \mathrm{C}$ did not yield any Si nanocrystal formation in this sample either. The atomic percentage Si concentration for this fluence at peak position of the $\mathrm{Si}$ distribution is estimated to be $2.6 \%$ with TRIM codes. ${ }^{17}$

Raman spectroscopy clearly demonstrates the formation and the evolution of $\mathrm{Si}$ nanocrystals in the $\mathrm{Al}_{2} \mathrm{O}_{3}$ matrix as a function of annealing temperature, as shown in Fig. 4. The evolution of the $\mathrm{Si}-\mathrm{Si}$ bonds, which shows the transformation from the amorphous phase to crystalline phase, can be observed from the variation of the Raman peaks seen at 150, 310 , and $480 \mathrm{~cm}^{-1}$ with the annealing temperature (Fig. 4). The bands measured at 150 and $310 \mathrm{~cm}^{-1}$ from the samples with high dose implantation diminish with increasing annealing temperatures and disappear almost completely after $1100{ }^{\circ} \mathrm{C}$ for $2 \mathrm{~h}$ annealing. We see that amorphous Si clusters formed in the as-implanted samples transform into crystalline Si structures with a more intense and narrow Raman signal as the annealing temperature increases. As is also observed by XRD, both the size and the number of Si nanocrystals increase with the increasing annealing temperature and the dose. The evolution of the TO band of Si nanocrystals is commonly considered as an indicator of crystallinity 
in $\mathrm{Si}$ structures. While amorphous $\mathrm{Si}$ has a broad $\mathrm{TO}$ band around $480 \mathrm{~cm}^{-1}$, bulk Si has a sharp TO band with a natural linewidth of approximately $3 \mathrm{~cm}^{-1}$ around $521 \mathrm{~cm}^{-1}$ at room temperature. Moreover, it is known that this band for nanocrystalline Si shows a broadening and a shift to lower wave numbers due to the phonon confinement effect. ${ }^{23}$ A qualitative comparison of the Raman signals measured for different doses and annealing temperatures indicates that while the nanocrystal formation starts at $800{ }^{\circ} \mathrm{C}$ for the sample with a dose of $2 \times 10^{17} \mathrm{Si} / \mathrm{cm}^{2}$, it begins at around $900{ }^{\circ} \mathrm{C}$ for the sample with a dose of $1 \times 10^{17} \mathrm{Si} / \mathrm{cm}^{2}$.

It was reported that the compressive stress can cause a shift to higher wave numbers, acting in the opposite direction to the phonon confinement effect. ${ }^{21}$ The competition between the two mechanisms determines the position of the peak. Therefore, the methods, developed for the size estimation of the Si nanocrystals by using the shift and the broadening of Si TO Raman signals, are questionable in the case of large stress as in the present case. ${ }^{24,25}$ Calculation of the size and the stress requires a separation between both parts from the Raman shift. The magnitude of the stress can be estimated from the stress induced wave number shift, $\Delta \omega_{s}:{ }^{26}$

$$
\sigma(\mathrm{MPa}) \approx 250 \Delta \omega_{s}\left(\mathrm{~cm}^{-1}\right),
$$

where $\sigma$ is the magnitude of the stress and $\Delta \omega_{s}$ is the stress induced wave number shift. In this calculation, the Raman shift due to the phonon confinement effect was first considered using results established by Campell and Fauchet, who calculated the relationship between the Raman shift and the size of the unstressed spherical nanocrystals using Gaussian a weighting function. ${ }^{24}$ Following to this calculation, the stress induced wave number shifts were found by subtracting these values from the corresponding experimental wave number values. The approximate magnitudes of the stress were calculated as $2.57,1.73$, and $1.71 \mathrm{GPa}$ in samples implanted with the dose of $2 \times 10^{17} \mathrm{Si} / \mathrm{cm}^{2}$ and subsequently annealed at 900,1100 , and $1000{ }^{\circ} \mathrm{C}$, respectively. Similarly, those values were calculated as 2.20 and $1.66 \mathrm{GPa}$ in samples with the dose of $1 \times 10^{17} \mathrm{Si} / \mathrm{cm}^{2}$ for annealing temperatures of 1000 and $1100{ }^{\circ} \mathrm{C}$, respectively. It seems that the amount of stress is larger on the smaller nanocrystals formed at lower temperatures and it reaches almost a constant value when the nanocrystal formation process is completed.

\section{Photoluminescence}

PL spectra of Si implanted $\mathrm{Al}_{2} \mathrm{O}_{3}$ matrix exhibit mainly three peaks in the visible region. Of these, the emission at around $694 \mathrm{~nm}$ is due to $\mathrm{PL}$ from $\mathrm{Cr}^{3+}$ impurities in the matrix $^{15}$ and the emission at around $740 \mathrm{~nm}$ may due to $\mathrm{Ti}^{3+} \cdot{ }^{27,28}$ The latter peak also exists in the case of $\mathrm{Ar}^{+}, \mathrm{Al}^{-}$, and $\mathrm{O}^{-}$implanted $\mathrm{Al}_{2} \mathrm{O}_{3} \cdot{ }^{15,28}$ However, as reported by others, ${ }^{13-15}$ the PL band seen at $570 \mathrm{~nm}$ appears after ion implantation followed by subsequent annealing and both its intensity and position may vary with increasing annealing temperatures. The origin of this emission is controversial. The discussions are mainly focused on three mechanisms; size dependent light emission from $\mathrm{Si}$ nanocrystals, ${ }^{14,15}$

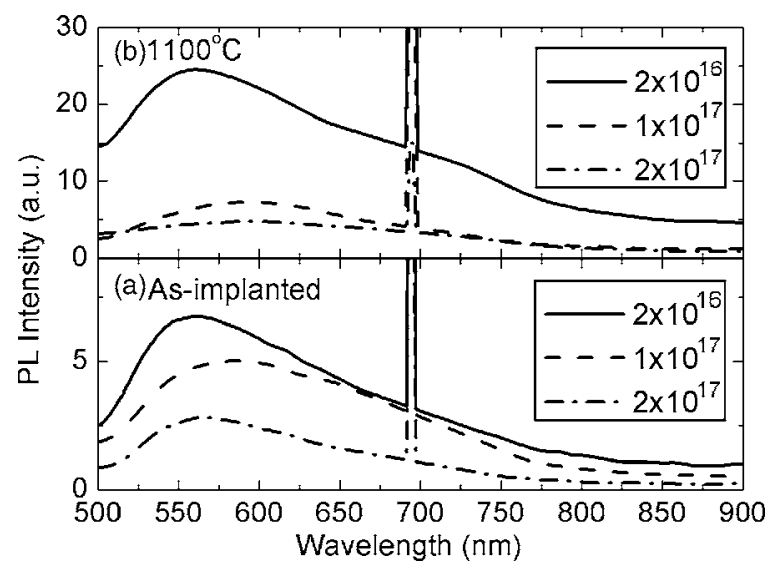

FIG. 5. PL spectra of (a) as implanted and (b) $1100{ }^{\circ} \mathrm{C}$ annealed samples of varying doses.

emission from Si clusters or from very small nanocrystals, ${ }^{28}$ and emission from matrix defects, mainly $\mathrm{F}$ center related defects. $^{13}$

The PL spectra [Fig. 5(a)] of the as-implanted samples with varying doses display three PL bands at around $570 \mathrm{~nm}$, $694 \mathrm{~nm}$, and a shoulder around $710 \mathrm{~nm}$. The latter two bands are assigned to $\mathrm{Cr}^{3+}$ and $\mathrm{Ti}^{3+}$ impurities, respectively. Having no indication of Si nanocrystal formation from the XRD and Raman measurements, the PL signal seen at $570 \mathrm{~nm}$ in the as-implanted samples is thought to be due to $\mathrm{F}_{2}^{2+}$ (two oxygen vacancies with two trapped electrons), ${ }^{29-31}$ introduced into the $\mathrm{Al}_{2} \mathrm{O}_{3}$ matrix during ion implantation. The intensity of the PL band at $570 \mathrm{~nm}$ in the as-implanted samples decreases with the implantation dose, indicating that the luminescent centers created by the ion implantation are quenched by additional implantation. ${ }^{32}$ This decrease may result from the annihilation of the luminescence centers due to either destruction of the light emitting structures formed by $\mathrm{Si}$ implantation at low doses or formation of new nonradiative centers which dominates the transitions. Contrary to the dose effect, high temperature annealing at $1100{ }^{\circ} \mathrm{C}$ results in an enhancement of the PL peak for all implantation doses. The variation is highest for the lowest dose of $2 \times 10^{16} \mathrm{Si} / \mathrm{cm}^{2}$. However, neither amorphous nor crystalline Raman features were observed from implanted samples with this dose. Furthermore, no clear shift was observed in PL spectra during phase transformation of the clusters from amorphous to crystal structures observed with Raman spectroscopy. The quantum confinement model suggests a redshift with nanocrystal size. Lack of shift in the PL spectra indicates that the observed light emission is not related to the excitonic transitions that take place in the core of the nanocrystals. This is further supported by the fact that the PL signal diminishes with increased dose for which the nanocrystal formation is clearly monitored by Raman spectroscopy and XRD (Figs. 1-4). The origin of the PL signal at $570 \mathrm{~nm}$ may be connected to point defects such as $\mathrm{F}_{2}^{2+}$ centers formed in the matrix by ion implantation. The lack of PL signal from the nanocrystals may be a result of large stress on nanocrystals as evidenced by Raman spectroscopy. The stress can break the bonds at the interface and be responsible for the creation of nonradiative centers around the nanocrystals. Another 
speculation might be the lack of $\mathrm{Si}=\mathrm{O}$ bonds which are believed to be responsible for the light emission from $\mathrm{Si}$ nanocrystals formed in $\mathrm{SiO}_{2}$ matrix. ${ }^{33}$

\section{CONCLUSIONS}

The formation of $\mathrm{Si}$ nanocrystals in $\mathrm{Al}_{2} \mathrm{O}_{3}$ matrix by ion implantation and subsequent annealing is studied with Raman spectroscopy, XRD, and PL spectroscopy. The nanocrystal sizes are obtained from the width of Si (111) XRD pattern by applying Scherrer's formula. In agreement with the expectations from the lattice mismatch between Si nanocrystals and the host matrix, large amount of compressive stress is estimated from the analysis of the Raman signal. Since the as-implanted samples possess similar emission features and center of the band does not shift during the formation of nanocrystals, the origin of the PL band around $570 \mathrm{~nm}$ was considered as defect related. The corresponding defect is assumed as an $\mathrm{F}_{2}^{2+}$ center. The reason for the absence of nanocrystal related PL may be due to the extraordinary compressive stress on $\mathrm{Si}$ nanocrystals or the lack of $\mathrm{Si}=\mathrm{O}$ bonds in $\mathrm{Si}-\mathrm{nc} / \mathrm{Al}_{2} \mathrm{O}_{3}$ structures.

\section{ACKNOWLEDGMENTS}

This work has been partially supported by the European Commission through the FP6 project called SEMINANO under Contract No. NMP4-CT-2004-505285. The authors thank Professor E. Bulur for the helpful discussion on the $F$ center defects.

${ }^{1}$ L. T. Canham, Appl. Phys. Lett. 57, 1046 (1990).

${ }^{2}$ K. D. Hirschman, L. Tsybeskov, S. P. Duttagupta, and P. M. Fauchet, Nature (London) 384, 338 (1997).

${ }^{3}$ U. Serincan, G. Aygun, and R. Turan, J. Lumin. 113, 229 (2005).

${ }^{4}$ Z. Lu, J. Shen, B. Mereu, M. Alexe, R. Scholz, V. Talalaev, and M. Zacharias, Appl. Phys. A: Mater. Sci. Process. 80, 1631 (2005).

${ }^{5}$ V. Lehman, and U. Gosele, Appl. Phys. Lett. 61, 1948 (1991).

${ }^{6}$ X. Y. Chen, Y. F. Lu, L. J. Tang, Y. H. Wu, B. J. Cho, X. J. Xu, J. R. Dong, and W. D. Song, J. Appl. Phys. 97, 014913 (2005).

${ }^{7}$ L. Khriachtchev, O. Kilpela, S. Karirinne, J. Keranen, and T. Lepisto,
Appl. Phys. Lett. 78, 323 (2001).

${ }^{8}$ M. Prokes, Appl. Phys. Lett. 62, 3244 (1993).

${ }^{9}$ Y. Zhu, H. Wang, and P. P. Ong, J. Phys. D 33, 2687 (2000).

${ }^{10}$ T. Baron, A. Fernandes, J. F. Damiencourt, B. De Salvo, F. Martin, F. Mazen, and S. Haukka, Appl. Phys. Lett. 82, 4151 (2003).

${ }^{11}$ L. Bi and J. Y. Feng, J. Lumin. 121, 95 (2006).

${ }^{12}$ Q. Wan, N. L. Zhang, X. Y. Xie, T. H. Wang, and C. L. Lin, Appl. Surf. Sci. 191, 171 (2002).

${ }^{13}$ M. Kokonou, A. G. Nassiopoulou, and A. Travlos, Mater. Sci. Eng., B 101, 65 (2003).

${ }^{14}$ S. Yanagiya and M. Ishida, J. Electron. Mater. 28, 498 (1999).

${ }^{15}$ C. J. Park, Y. H. Kwon, Y. H. Lee, T. W. Kang, H. Y. Cho, S. Kim, S. H. Choi, and R. G. Elliman, Appl. Phys. Lett. 84, 2667 (2004).

${ }^{16}$ D. I. Tetelbaum, A. N. Mikhaylov, O. N. Gorshkov, A. P. Kasatkin, A. I. Belov, D. M. Gaponova, and S. V. Morozov, Vacuum 78, 519 (2005).

${ }^{17}$ J. F. Ziegler, J. P. Biersack, and U. Littmark, The Stopping and Range of Ions in Solids (Pergamon, New York, 1985).

${ }^{18}$ M. Morales, Y. Leconte, R. Rizk, and D. Chateigner, J. Appl. Phys. 97, 034307 (2004).

${ }^{19}$ D. Comedi, O. H. Y. Zalloum, E. A. Irving, J. Wojcik, T. Roschuk, M. J. Flynn, and P. Mascher, J. Appl. Phys. 99, 023518 (2006).

${ }^{20}$ H. P. Klug and L. E. Alexander, X-Ray Diffration Procedures (Wiley, New York, 1974).

${ }^{21}$ G. Viera, S. Huet, and L. Boufendi, J. Appl. Phys. 90, 4175 (2001).

${ }^{22}$ T. Zheng and Z. Li, Superlattices Microstruct. 37, 227 (2005).

${ }^{23}$ D. Nesheva, C. Raptis, A. Peraklis, I. Bineva, Z. Aneva, Z. Levi, S. Alexandrova, and H. Hofmeister, J. Appl. Phys. 92, 4678 (2002).

${ }^{24}$ I. H. Campbell and P. M. Fauchet, Solid State Commun. 58, 739 (1986).

${ }^{25} \mathrm{Ch}$. Ossadnik, S. Veprek, and I. Gregora, Thin Solid Films 337, 148 (1999).

${ }^{26}$ J. Marcia, E. Martin, A. Perez-Rodriquez, J. Jimenez, J. M. Morante, B. Aspar, and J. Margial, J. Appl. Phys. 82, 3730 (1997).

${ }^{27}$ L. E. Bausa, I. Vergara, F. Jaque, and J. Garcia Sole, J. Phys.: Condens. Matter 2, 9919 (1990).

${ }^{28}$ D. I. Tetelbaum, O. N. Gorshkov, A. V. Ershov, A. P. Kasatkin, V. A. Kamin, A. N. Mikhaylov, A. I. Belov, D. M. Gaponova, L. Pavesi, L. Ferraioli, T. G. Finstad, and S. Foss, Thin Solid Films 515, 333 (2006).

${ }^{29}$ Y. Song, C. H. Zhang, Z. G. Wang, Y. M. Sun, J. L. Duan, and Z. M. Zhao, Nucl. Instrum. Methods Phys. Res. B 245, 210 (2006).

${ }^{30}$ T. Mohanty, N. C. Mishra, F. Singh, S. V. Bhat, and D. Kanjilal, Radiat. Meas. 36, 723 (2003).

${ }^{31}$ T. Mohanty, N. C. Mishra, F. Singh, U. Tiwari, and D. Kanjilal, Nucl. Instrum. Methods Phys. Res. B 212, 179 (2003).

${ }^{32}$ K. S. Jheeta, D. C. Jain, F. Singh, R. Kumar, and K. B. Garg, Nucl. Instrum. Methods Phys. Res. B 224, 187 (2006).

${ }^{33}$ L. Khriachtchev, M. Rasanen, S. Novikov, and L. Pavesi, Appl. Phys. Lett. 85, 1511 (2004). 